\title{
The Study of Sustainable Logic Running in "Songs of Bu Luo Tuo” of Zhuang Ethnic Minority
}

\author{
Qianwei Jin \\ Center for Post-doctoral Studies of Liberal Arts College \\ Hunan Normal University \\ Changsha, China 410081 \\ School of Art and Culture \\ Guangxi University of Science and Technology \\ Liuzhou, China 545006
}

\begin{abstract}
Subjects of Zhuang creation show their brilliance in the creation of Songs of Bu Luo Tuo. The text with the properties of nature worship, totem worship, ancestor worship shapes the universal ancestor god Buluotuo becoming the spirit of ethnic members of solidarity and coordination of actions. It reflects the sustainable development concept of people and nature depending on each other, people loving each other, and man and society in an orderly and harmonious atomosphere. It is the logic running that makes the ecological value of Buluotuo cultural heritage protection.
\end{abstract}

Keywords-Songs of Bu Luo Tuo of Zhuang; sustainable development; logical operation

Ancestors in Zhuang ethnic minority created Songs of Bu Luo Tuo in the form of sacred region according to the survival experience of ethnic group in secular society including lifestyle, production skill, living wisdom and so on to construct the text carefully. It tells the rules of the genesis of the world, all the survival and reproduction of the world by folk oral transmission of discourse. Buluotuo is portrayed as universal ancestral wisdom of God. Studying the relevant texts seriously, it will be found that the text presents the concept of sustainable development, the logical operation in it reflects the ecological value that ancestors created the text.

\section{THE LOGIC RUNNING OF THE CREATIVE SUBJECT CONCEPTION}

The myth, epics, legends, and rituals of the birth of human mostly answered the originality of genesis of the world and the lives of all things. Our ancestors as creative subject showed their excellent wisdom in the creation of the culture form fully, not only for the contemporary era, but the past, also they pay more attention to the possible changes of future development. In this way, they had an overall imagination of the past, present and the future through sustainable thoughts.

\section{A. Forming conception of Songs of Bu Luo Tuo}

The creative subjects of ancestors need the almighty God that they have created to ensure their peaceful life and property in safe for humans did not show special creative ability. As a part of the world, it is possible that they have some different manners of walking upright compared with other tetrapods, but they also need to struggle for life just like other creatures. Faced with the limited resources, pillage and fight always happen in different groups, and casualties maybe caused. Therefore, insuring personal security is a burning question, which refers to the problem of how do people get along well with others and nature.

Binding rules of conduct fromed by the accumulation of long-term life experience are used to protect the benefits of groups for people in the contemporary times having no ability to change the living envoronment, so the creative subjects create Songs of Bu Luo Tuo by means of imagination. The conception admits the mystery relationship between human and God and gives a brief answer to the origin of the universe, the formation of rivers and mountains, and the change rules of the sun, moon and stars. The view of animism thinks that the power of myth is invisible and cannot be touched but very powerful, and it holds the belief that the similarities of the universe including human is the soul. Besides, any forces disturbing the soul of plants and animals will be punished, only harmonious coexistence can insure a peaceful life. So, the reverence derives out nature worship, totem worship, ancestor worship to limit people's behaviors to deprive of resources, and it limits obessive demand of young people and so on. Songs of Bu Luo Tuo is created to guarantee a peaceful and orderly social life by the holiness of folk belief.

\section{B. The logic objective of the image of Buluotuo ancestor}

Buluotuo belongs to the Gods that Zhuang ethnic group created. Buluotuo, formerly known as "FuLuotuo", the former is the translation of Chinese. The meaning of "Fu" in Zhuang is a honorific to the venerable old men; "Luo" is to know and understand; "Tuo" means universality and entirety. Putting the words together means omniscient and wise old men. Ancestors attributed the history and culture created by ethnic, and harmonious and orderly social order to the Buluotuo. "In myths and legends and epic, Buluotuo is the creation and ancestor of God of ancient times; in modern stories and legends, he is a venerable leader and great wizard in early society of Zhuang ethnic minority. 
In ancient times, individuals or groups have not enough power to resist outside forces. Obviously, they can not solve the natural phenomenon of mental and spiritual fear, only by pining their hopes in the spirit of mysterious witchcraft, also they created a variety of powerful gods to resist against demons and ghosts for ethnic, and formed their worship and respect of supernatural power based on the psychology restraining the behavior of people, adjusted the relationship between people, and promoted the harmonious development of the society. Therefore, Buluotuo had become the indigenous human ancestor of the nation living in Pearl River and was worshipped as the God of creation, the ancestor of God, religion and God of morality. The belief of Buluotuo is a kind of spiritual power of tribal society uniting and coordinating. Any words that bind people's behaviors are sent by the universal and wise God, especially the formation of the sacred folk religion of Zhuang ethnic minority is influenced deeply by the special emotion of ancestors worshipping, which is the brilliant move of shapping ancestors.

\section{C. self-discipline of secular society for surviving}

Songs of Buluotuo is a religious textbook, from first to last it tells that people in the history of Zhuang ancestors worship for progenitors and pray for happiness of life. Seeing from the poem's content, it traced back to the time of human savagery and chaos, but also took the early disintegration of primitive society until the class society into account. It can be said to describe the origin from heaven to the ground, from God to man, and from the universe to the great God. As the primitive religion of the Zhuang nationality, nature worship, ancestor worship, and polytheism exist. In the world of Zhuang people's belief, Buluotuo is omnipotent, in general, Buluotuo produced a variety of cultural artifacts for people to teach all kinds of production and living skills making customs of weddings and funerals, festivals and etiquette ethics. In all, everything in the world, the existing way of all things and the rules of doing are created and arranged by Buluotuo. It relates to the all aspects of society and culture, therefore, enjoys the reputation of "Encyclopedia in Zhuang".

Sustainable development focus on the future. Therefore, integrating the unique ethnic emotion, spirit and behavior rules into Buluotuo belief with the nature of the folk belief can provide reference in line with the traditional cultural habitus for the people's behaviors, Buluotuo belief as an ethnic spiritual and cultural achievement has a deep influence on it. People worshipping Buluotuo for a long term compiled it into melodious poetry, which made the ancient myths and legends be handed down to remember and tell easily. Buluotuo gives deep influence on spirit of ethnic groups, especially using religious worship to guide and constraint people to achieve the effect of group members being self-discipline for social harmony. Taking its function to say, restricting all members of words and deeds under the name of the ancestors of God Buluotuo can achieve a harmonious and orderly life of ethnic groups so as to make the society of Zhuang ethnic minority be stable, harmonious and develop smoothly.

\section{ACCEPTANCE OF LOGIC RUNNING THAT SUBJECTS WORSHIP FOLLOWS}

Songs of Buluotuo is a folk religious text in Zhuang, and it describes the relationship between heaven and earth, God and human beings with distinctive ethnic characteristics of poetry, and has positive effects on acceptance subjects, the main performance is that people and nature depend on each other, and the sustainable development of ecological concept of harmonious coexistence. Its operation of text logic is to construct an ecological, unity and orderly, loving and harmonious society.

\section{A. people and nature: interdependent and sharing a good ecological environment}

Zhuang ethnic minority realizes human's dependence on nature in surviving. It shows an ethical value of nature and connects with the idea of animism closely. It gives a mysterious soul to all creatures in the world, and uses the logic of karma as the rules of harmonious relationship between human and nature for human cannot squeeze natural resources blindly to development but depending on each other. Songs of Buluotuo shows nature and totem worship, even a kind of special emotion by the expression of grateful consciousness, which is an emotional activity and group consciousness.

The interdependent relationship between man and nature, as Buluotuo belief said, is mainly reflected in sacrificial rituals the of spring and autumn, which is held in the slack season and divided into spring and autumn festival. The first extends from the beginning of the lunar new year in February, nineteen to the ninth lunar month, the second is the autumn after the lunar month of October, namely, folk beliefs of people that praying in spring and offering thanks in autumn. The factors that holding time, number and size, the sacrifice of the content are not the same. Spring is the season of recovery in all things and people pray for good weather, the harvest production, affluent life through the ritual, and eager to have a satisfactory harvest in autumn and higher income families, more sources of income, and enjoy rich and good days. The sacrifice to ancestors and God Buluotuo also provides grains and livestock of material life, because it is hoped to have a good weather and harvest in Zhuang ethnic group. Text in the souls of grains redemption holds the belief that people frightened the soul of rice and caused the lack of grain; because of pulling the plow in the fields for a long time, farm cattle were too tired, so they would disturb the soul of cattle. Only by inviting Buluotuo to settle their souls, will people be able to enjoy the joy of harvest. The behaviors that people and animals and plants depending on each other belong to the ecological model of harmonious coexistence of man and nature.

\section{B. People to people: sharing love with each other.}

Harmony in family emphasizes loving and cherishing each other between family members, and work together to create a sincere human feelings to let the elderly and young children live in the world of love entirely, but thousands of families will also have contradiction, sometimes even quarrel utter confusion, at this time praying for ancestor Buluotuo's attunement is very important. People can resolve grievances 
among family members through a series of words and deeds of the ritual activities to establish a happy and harmonious relationship.

The closest relation among family members is parentchild relationship, such as Chapter VII of the text describes "solving the problems between father and son ": "father asked his son for cooking, the son rubbed his palm; father ate breakfast and went fishing; the son strolled; after meals father dredged canals, but the son dropped around over smoking a cigarette; father urged son to mount plough and harrow; son pulled out a weapon towards father; father urged the child to the farm; the son lifted feet toward father; father urged the son to build balustrade; the son made rude marks to father; beyond father's patience, he lessoned son with knives; however, the son seized his axe to cut the father; ever since the rancor incurred; the father cursed to the sky to make the son lack grain, domestic animals are not thriving, have no children, then the curse achieved. Later, the son asked for BuLuoTuo for advice devoutly and realized that his behaviors have offend Gods, so he prepared oblation and held rituals to dissolve the resentments, and the son and his father reconciled. Actually, it tells the virtue of respecting and caring for the young, hard-working and frugal, the fraternity through folk belief. In addition to a quarrel between father and son, there are quarrels between mother and daughter, brothers discord against each other, old woman grudges daughter-in-law and so on. All of these will cause discord in the family, and people cannot enjoy family warmth. However, by chanting about the poem by "solution of injustice" in a specific ritual, sorcerers can promote loving truth, chant scriptures, and parties accept the scriptures sincerely can get rid of discretion, the purpose is to guide people in the name of the ancestor Buluotuo to cherish the destiny between family members and construct the world of family positively to let family members show the true love in the world.

\section{C. people and society: harmonious and orderly sharing of friendship in the world}

In 2002, after experts and scholars' sufficient investigation and argumentation, it is thought that Gan Zhuang Shan in Tianyang, Guangxi is cultural sites of Zhuang ancestor Buluotuo, also known as the sacred mountains. According to the investigation, the custom of worshipping Buluotuo in Zhuang folk has existed since Tang Dynasty, at least more than 1000 years of history. On annual ancestral God Buluotuo birthday, tens of thousands of Zhuang people from all directions went to Gan Zhuang Shan to hold Buluotuo sacrificial ceremony, the number could even reach more than two or three million.

In May 2006, Buluotuo oral literature is included in the national cultural heritage, as a symbol of Zhuang civilization, this is the ethnic admiration and worship towards first human ancestor Buluotuo's important contribution to the survival and development of human. Because Buluotuo is portrayed as the omnipotent God who could solve all problems for human and left a valuable spiritual wealth to later generations. The folk people having long-term worship of Buluotuo wrote it into catchy and melodious poetry.
Buluotuo has become the culture symbols of standard words and deeds. It can be said that from the analysis of religious feelings in Zhuang nationality, the whole society faces ethical norms advocated by Buluotuo culture positively, and it has developed combined with the new era. Besides, it absorbs the beneficial nutrients of Buluotuo culture, especially is very valuable for the construction of justice and stability, harmonious and orderly society. The early realization of ideal goal of being honest and trustworthy, willing to help others, and living and working in peace needs everyone to work together to maintain the sustainable development of good social environment and create a harmonious, friendly world between man and society in the 21 st century.

Songs of Buluotuo bears the special emotion of Zhuang's folk beliefs, and it advocates social members with reverence and awe heart consciously to protect the ecological environment, actively practice the ethics of respecting the old and cherishing the young, pursue the interpersonal relationship of harmony and warmth positively, and create a loving and actively social environment. The creative subjects and receptions guarantee the sustainable development of logic running in the text jointly.

\section{REFERENCES}

[1] Xu Ganli. The Possibility of Folk Belief Culture Heritabilization Taking Buluotuo Culture Sites as Example [J]. Journal of Southwest University for nationalities, 2010 (4).

[2] Mou Zhongjian. Seeing Zhuang Buluotuo Belief from the Perspective of Science of Religion [J]. Study of Ethnics in Guangxi, 2005 (2) 